\title{
Photosynthetic heat tolerance in wheat: Evidence for genotype-by-environment interactions
}

\author{
Onoriode Coast ${ }^{1}$, Bradley Posch ${ }^{1}$, Bethany Rognoni ${ }^{2}$, Helen Bramley ${ }^{3}$, Oorbessy Gaju ${ }^{1}$, \\ John MacKenzie ${ }^{1}$, Claire Pickles ${ }^{4}$, Alison Kelly ${ }^{2}$, Meiqin Lu ${ }^{5}$, Yong-Ling Ruan ${ }^{6}$, Richard \\ Trethowan $^{3}$, and Owen Atkin ${ }^{1}$ \\ ${ }^{1}$ Australian National University \\ ${ }^{2}$ Queensland Department of Agriculture and Fisheries \\ ${ }^{3}$ The University of Sydney \\ ${ }^{4}$ Birchip Cropping Group \\ ${ }^{5}$ Australian Grain Technologies, 12656 Newell Highway Locked Bag 1100 Narrabri NSW \\ 2390 \\ ${ }^{6}$ The University of Newcastle
}

October 25, 2021

\begin{abstract}
High temperature stress inhibits wheat photosynthetic processes and threatens wheat production. Photosynthetic heat tolerance (commonly measured as $T_{\text {crit }}$ - the critical temperature at which incipient damage to photosystem II occurs) in wheat genotypes could be improved by exploiting genetic variation and genotype-by-environment interaction (GEI) for this trait. Flag leaf $T_{\text {crit }}$ of a total of 54 wheat genotypes were evaluated in 12 thermal environments over three years in Australia using linear mixed models for assessing GEI effects. Nine of the 12 environments had significant genotypic effect and highly variable broad-sense heritability $\left(\mathrm{H}^{2}\right.$ ranged from 0.15 to 0.75$)$. $T_{\text {crit }}$ GEI was variable, with $55.6 \%$ of the genetic variance across environments accounted for by the factor analytic model. Mean daily growth temperature preceding anthesis was the most influential environmental driver of $T_{\text {crit }}$ GEI, suggesting varied scales of biochemical, physiological, and structural adaptations to temperature requiring different durations to manifest at the thylakoid membrane and leaf levels. These changes help protect or repair photosystem II upon exposure to heat stress. To support current wheat breeding, we identified genotypes superior to commercial cultivars commonly grown by farmers, and showed that there is potential for developing genotypes with greater photosynthetic heat tolerance.
\end{abstract}

\section{Title}

Photosynthetic heat tolerance in wheat: Evidence for genotype-by-environment interactions

\section{Running Title}

Wheat $T$ crit GEI

\section{Authors}

Onoriode Coast ${ }^{1,2,3^{*}}$, Bradley C. Posch ${ }^{1}$, Bethany G. Rognoni ${ }^{*}$, Helen Bramley ${ }^{5}$, Oorbessy Gaju ${ }^{1,6}$, John Mackenzie $^{1}$, Claire Pickles ${ }^{7}$, Alison M. Kelly ${ }^{4,8}$, Meiqin Lu ${ }^{9}$, Yong-Ling Ruan ${ }^{10}$, Richard Trethowan ${ }^{5,11}$, Owen K. Atkin ${ }^{1}$

\section{Contact Information}


${ }^{1}$ ARC Centre of Excellence in Plant Energy Biology, Research School of Biology, The Australian National University, Canberra, ACT 2601, Australia; ${ }^{2}$ Natural Resources Institute, University of Greenwich, Central Avenue, Chatham Maritime, Kent ME4 4TB, United Kingdom; ${ }^{3}$ School of Environmental and Rural Sciences, Faculty of Science Agriculture Business and Law, University of New England, Armidale, NSW 2351, Australia; ${ }^{4}$ Department of Agriculture and Fisheries, Leslie Research Facility, Toowoomba QLD 4350, Australia; ${ }^{5}$ School of Life and Environmental Sciences, Plant Breeding Institute, Sydney Institute of Agriculture, The University of Sydney, Narrabri, NSW 2390, Australia; ${ }^{6}$ Lincoln Institute of Agri-Food Technology, University of Lincoln, Riseholme Park, Lincoln, Lincolnshire, LN2 2LG, United Kingdom; ${ }^{7}$ Birchip Cropping Group, 73 Cumming Avenue, Birchip, VIC 3483, Australia; ${ }^{8}$ Queensland Alliance for Agriculture and Food Innovation, The University of Queensland, Toowoomba QLD 4350, Australia; ${ }^{9}$ Australian Grain Technologies, 12656 Newell Highway, Narrabri, NSW 2390, Australia; ${ }^{10}$ Australia-China Research Centre for Crop Improvement and School of Environmental and Life Sciences, The University of Newcastle, Callaghan, NSW 2308, Australia; ${ }^{11}$ School of Life and Environmental Sciences, Plant Breeding Institute, Sydney Institute of Agriculture, The University of Sydney, Cobbitty, NSW 2570, Australia

${ }^{*}$ Corresponding authors:

Onoriode Coast (onoriode.coast@anu.edu.au; https://orcid.org/0000-0002-5013-4715)

Bethany G. Rognoni (bethany.rognoni@daf.qld.gov.au; https://orcid.org/0000-0002-1082-4201)

\title{
Funding
}

ARC Centre of Excellence in Plant Energy Biology (CE140100008)

Australian Grains Research and Development Corporation (GRDC) Postdoctoral Fellowship: "Photosynthetic Acclimation to High Temperature in Wheat" (US1904-003RTX - 9177346) and National Wheat Heat Tolerance Project (US00080).

\begin{abstract}
High temperature stress inhibits wheat photosynthetic processes and threatens wheat production. Photosynthetic heat tolerance (commonly measured as $T$ crit - the critical temperature at which incipient damage to photosystem II occurs) in wheat genotypes could be improved by exploiting genetic variation and genotypeby-environment interaction (GEI) for this trait. Flag leaf $T$ crit of a total of 54 wheat genotypes were evaluated in 12 thermal environments over three years in Australia using linear mixed models for assessing GEI effects. Nine of the 12 environments had significant genotypic effect and highly variable broad-sense heritability $\left(\mathrm{H}^{2}\right.$ ranged from 0.15 to 0.75$). T$ crit GEI was variable, with $55.6 \%$ of the genetic variance across environments accounted for by the factor analytic model. Mean daily growth temperature preceding anthesis was the most influential environmental driver of $T$ crit GEI, suggesting varied scales of biochemical, physiological, and structural adaptations to temperature requiring different durations to manifest at the thylakoid membrane and leaf levels. These changes help protect or repair photosystem II upon exposure to heat stress. To support current wheat breeding, we identified genotypes superior to commercial cultivars commonly grown by farmers, and showed that there is potential for developing genotypes with greater photosynthetic heat tolerance.
\end{abstract}

\section{Key words:}

factor analytic models, heat stress, multi-environment trial, photosynthetic thermal tolerance, photosystem II, Triticum aestivum

\section{Introduction}

Photosynthesis is an important determinant of plant biomass and crop yield. High temperature (warmer nights and days, and heatwaves) can negatively impact photosynthesis resulting in reduced crop yield. Global warming has been correlated with worldwide wheat (Triticum aestivum L.) yield losses (Asseng et al., 2015, 2017; Zhao et al., 2017). Additionally, there are model predictions of wheat yield decreases of up to $6 \%$ per 
$1^{\circ} \mathrm{C}$ increase in temperature (Zhao et al., 2017). In Australia, wheat yield loss due to high temperature is estimated to cost $\$ 1.1$ billion per annum (GRDC, 2018). The impact of high temperature on wheat yield in Australia potentially affects global wheat availability and food security, considering Australia accounts for about $11 \%$ of global wheat exports (ABARES, 2021; Qureshi et al., 2013). Mean surface air temperature across Australia has warmed on average by $1.44^{\circ} \mathrm{C}$ since 1910 , with most warming occurring since 1950 (BOM and CSIRO, 2020). This has led to longer, more intense, and frequent heatwaves. This trend is predicted to continue, with some models predicting increases in annual mean temperature of approximately $0.44-$ $2.47^{\circ} \mathrm{C}$ by mid-century (Climate Change Australia, 2021). To better adapt wheat production in Australia to warming, it is pertinent that genotypes with traits that confer heat tolerance are identified and incorporated into breeding programmes. One such trait is photosynthetic heat tolerance.

Photosynthetic heat tolerance is often inferred from measures of leaf chlorophyll- $a$ fluorescence (Geange et al., 2020) - light emitted by chloroplasts due to changes in the status of photosystem II (PSII) complexes embedded within the thylakoid membrane (Maxwell and Johnson, 2000). A commonly used chlorophyll$a$ fluorescence parameter is the maximum quantum efficiency of PSII $\left(\mathrm{F}_{\mathrm{V}} / \mathrm{F}_{\mathrm{M}}\right)$, defined as the ratio of variable fluorescence (difference between the basal chlorophyll-afluorescence, $\mathrm{F}_{0}$, and maximum chlorophyllafluorescence, $\mathrm{F}_{\mathrm{M}}$ ) to maximum fluorescence. $\mathrm{F}_{\mathrm{V}} / \mathrm{F}_{\mathrm{M}}$ has been applied in mass screening of wheat cultivars for high temperature tolerance (Azam et al., 2015; Sharma et al., 2012, 2017). Another chlorophyll- $a$ fluorescence measure for assessing photosynthetic heat tolerance is the critical temperature of PSII function $(T$ crit $) . T$ crit is determined as the temperature at which $F_{0}$ rises abruptly with increase in temperature signifying the onset of damage to PSII (Berry and Bjorkman, 1980; Schreiber and Berry, 1977). T crit is widely used in ecological studies (Hüve et al., 2006; Knight and Ackerly, 2002; O'Sullivan et al., 2017; Zhu et al., 2018) and thought to be a more sensitive measure of thermal damage to PSII function than $\mathrm{F}_{\mathrm{V}} / \mathrm{F}_{\mathrm{M}}$ (Lin, 2012; Marias et al., 2017). $T$ crit is also relatively easier to measure than $F_{V} / F_{M}$ because it does not need a saturating pulse and re-dark adaptation. The recent development of high-throughput phenotyping tools for measuring $T$ crit (Arnold et al., 2021) has made it possible to include measurements of $T$ crit in large scale trials, typical of breeding programmes.

$T$ crit responds to changes in growth environment conditions and varies among species (Lancaster and Humphreys, 2020; O'Sullivan et al., 2017; Rekika et al., 1997; Zhu et al., 2018). Genetic gains in breeding for high temperature tolerance could be improved with information from experiments that account for both genotype and environment main effects, and their interaction, on $T$ crit. Genotype-by-environment interaction (GEI) characterises the differential response of genotypes to a change in the environment and is a common impediment to selection of superior genotypes. GEI is the primary reason why breeders conduct multienvironment trials (MET, a set of connected trials across multiple years and environments). Incorporating measurements of $T$ crit in MET can provide useful information on yield stability and adaptability of genotypes to defined environment types (or the target population of environments; Comstock, 1977). Multi-environment trials are often highly unbalanced, and analysis of these data using traditional methods such as ANOVA are typically inadequate (Smith et al., 2015). A more flexible and superior approach for MET analysis uses factor analytic (FA) models (Smith et al., 2001). Factor analytic models combined with graphical tools, such as latent regression plots and heatmaps of the estimated genetic correlation matrix across environments (Smith and Cullis, 2018; Smith et al., 2015) can be used to explore GEI, and identify superior genotypes (with high performance and stability across the target population of environments). Additionally, loadings from FA models can be linked with environmental covariates to identify important environmental drivers of $T$ crit GEI. This approach has been used to explore trends in species performance across environments in both plant and animal studies such as wheat yield in India (Trethowan et al., 2018), lodging tolerance in spring wheat (Dreccer et al., 2020), sorghum [Sorghum bicolor (L.) Moench] biomass under drought (Oliveira et al., 2020) and body weight at harvest of the farmed fish species - rainbow trout (Onchorynchus mykiss ) (Sae-Lim et al., 2014).

We conducted MET comprising 12 thermal environments (across three years) in Australia with a total of 54 wheat genotypes, and assessed GEI effect on photosynthetic heat tolerance in wheat. The research objectives were: (i) to examine genotypic, environmental, and GEI effects on $T$ crit; (ii) to identify superior wheat 
genotypes (i.e. with consistently high and stable $T$ crit) for a range of Australian wheat growing conditions; and (iii) to identify the major environmental drivers of wheat $T$ crit GEI.

\section{Materials and Methods}

A total of 54 wheat genotypes (Table S1) were grown in eight field and four controlled environments over three years (2017-2019). Of these 54 genotypes, 20 were common to all environments. The eight field experiments were conducted in major wheat growing regions of Australia (Dingwall, Victoria in 2017, Barraport West, Victoria in 2018, and Narrabri, New South Wales in 2019). The field trials were sown one month apart over three months in 2017 and 2018, and two months apart in 2019, with the initial sowing time being the optimum sowing time for each region. Later sown plants were exposed to higher temperatures at the critical reproductive and grain-filling stages. Across the different trials, plants received water from a combination of rainfall and irrigation of 152-185 mm in Dingwall, 217-235 mm in Barraport West, and 363-492 $\mathrm{mm}$ in Narrabri between sowing and anthesis. Twenty genotypes were evaluated during the 2017 and 2018 trials, and 24 genotypes in 2019. The experimental designs, crop husbandry and data collection methods were similar across all three field experiments, except for the differences mentioned above (i.e. number of sowings and genotypes). A detailed description of the 2017 and 2018 experimental sites, designs and crop husbandry are reported in Coast et al. (2021) while those for the 2019 experiments are given below.

\section{Field Trial with 24 Genotypes}

\section{Experimental Site}

The 2019 field experiment was conducted at the Plant Breeding Institute (PBI; 30.27 ${ }^{\circ} \mathrm{S}, 149.81^{\circ} \mathrm{E}$; elevation $212 \mathrm{~m}$ above sea level) of The University of Sydney, Narrabri, NSW. Narrabri is characterised by hot summers and mild winters with a summer-dominant rainfall pattern. Long-term mean daily maximum and minimum temperatures during the wheat growing season at Narrabri range from $7.1-21.3^{\circ} \mathrm{C}$ in May (beginning to the season) to $11.4-26.94^{\circ} \mathrm{C}$ in October (during anthesis) and $16.9-32.1^{\circ} \mathrm{C}$ in December (at harvest). Mean rainfall from sowing (in May) to anthesis (in October) at Narrabri is $273 \mathrm{~mm}$. Temperature, relative humidity, rainfall, and windspeed data were recorded onsite with a weather station. The soil in Narrabri is a cracking montmorillonitic clay soil characterised as a grey vertosol (Isbell, 2002).

\section{Experimental Design of the 2019 Field Experiment}

The 2019 field experiment used a two-phase experimental design following the definition of Brien and Bailey (2006) to investigate response of $T$ crit of 24 genotypes to warmer growth conditions. This was employed to account for variation due to the experimental layout in the field (field phase) and on the 48-well plate used in the laboratory for determining $T$ crit (laboratory phase). The two-phase experimental design was implemented to decompose potential sources of variation into components, thus improving the estimate of treatment effects (Cullis et al., 2003; Curnow, 1959).

The field phase focussed on 24 wheat genotypes which formed part of a larger set of 30 wheat genotypes in a time of sowing (TOS) trial. The experiment was arranged in two trials (or main blocks) subdivided into four replicate blocks. The two main blocks represented early-sown (Narrabri TOS1) and late-sown (Narrabri TOS2) environments, and were treated as two trials with four replicate blocks each. Each replicate block consisted of 30 plots arranged in five rows and six columns. Wheat genotypes were randomly allocated to the plots within each replicate blocks following a randomised complete block design. Narrabri TOS1 was sown on 17 May 2019 (i.e. within the recommended sowing window for the Narrabri area) and Narrabri TOS2 was sown on 15 July 2019. Flag leaf tissue was taken from one randomly selected plant in each field plot (see Flag leaf sampling section below). A total of 192 leaf tissue samples from 24 genotypes, four blocks and two TOS were collected. These samples formed the experimental units for the laboratory phase of the experiment.

The laboratory phase of the experiment was based on an Incomplete Block Design across 12 blocks with 24 units per block, with the initial starting array generated from the CycDesigN package (VSN-International Ltd, Hemel Hempstead, UK). The laboratory design was split for each of the TOS, as a partially replicated design (Cullis et al., 2006) with 1.5 replicates of 96 treatments, where the 96 treatments comprised a factorial 
treatment structure of four field replicates by 24 genotypes. Laboratory analysis was conducted over six days: three consecutive days each for Narrabri TOS1 and Narrabri TOS2. Each day was comprised of two incomplete blocks. The starting Incomplete Block design was optimised for the layout of samples across the 48-well plate using the optimal design (od) package in R (Butler, 2013). The leaf samples were positioned across a $6 \times 8$ spatial array, based on the dimensions of the Peltier block described in the next section.

\section{Controlled Environment Trial with 50 Genotypes}

In addition to the field trials, a trial with 50 wheat genotypes (including 20 genotypes common to the field trials) were conducted in four high precision Growth Capsules, with independent control of temperature, relative humidity, and multispectral LED light. The Growth Capsules were managed by the Australian Plant Phenomics Facility (APPF) and Grain Phenomics Climate Facility at the Australian National University (ANU), Canberra (https://www.plantphenomics.org.au). Each Growth Capsule was comprised of two separate chambers $3.8 \mathrm{~m}$ wide x $1.1 \mathrm{~m}$ deep x $2.1 \mathrm{~m}$ high. These Growth Capsules are capable of simulating location-specific environmental conditions, including diurnal and seasonal changes and complex climate scenarios, thus enabling phenotypic comparison, and screening large numbers of genotypes across various environments. The chambers were used to dynamically simulate four environments. The four environments were two cool and two warm (approximately $5^{\circ} \mathrm{C}$ higher than the cool) wheat growing seasons, based on the 15-minute average temperature during the vegetative growth to anthesis period (June - October) of the six-year period 2013-2018 for the Narrabri site. Simulation of dawn, daylight and dusk timings also mimicked conditions in Narrabri. Lights were supplied by colour-adjustable LED modules which were kept thermally insulated from the plant growth area. The simulated environments will henceforth be identified as simulated cool season 1 (SIM-C1), simulated cool season 2 (SIM-C2), simulated warm season 1 (SIM-W1) and simulated warm season 2 (SIM-W2).

\section{Crop Husbandry}

Germinated seeds of the 50 wheat genotypes were sown into 6 L plastic pots (one seedling per pot) filled with Martins mix (Martins Fertilizers Ltd, Yass, NSW Australia). The Martins mix was supplemented with $4 \mathrm{~g}$ $\mathrm{L}^{-1}$ of Osmocote $\mathrm{R}$ OSEX34 EXACT slow-release fertiliser (Scotts Australia, Bella Vista, NSW, Australia) and treated at $63 \mathrm{degC}$ for $1 \mathrm{~h}$ prior to filling pots. Plants were grown for three weeks under glasshouse conditions at the ANU Controlled Environment Facilities, Canberra, Australia. In the glasshouse, plants were exposed to natural light with average daylength of $11.8 \mathrm{~h}$, and daily light integral of $14.9 \mathrm{~mol} \mathrm{~m}^{-2}$ $\mathrm{d}^{-1}$. Daily temperature and relative humidity were on average $19.4 \mathrm{deg} C$ and $54.8 \%$, respectively. Thereafter plants were transferred to the high precision Growth Capsules described earlier where they were initially kept for one week at day:night temperature of $20: 15 \mathrm{degC}$, and photosynthetically active radiation at plant height of $500-600 \mu \mathrm{mol} \mathrm{m} \mathrm{s}^{-1}$ on a $12 \mathrm{~h}$ photothermal regime. Afterwards, the environmental conditions within the chambers were programmed to either a cool (SIM-C1 and SIM-C2) or warm (SIM-W1 and SIM-W2) thermal regime. General plant management followed the established protocol of the APPF and Grain Phenomics Climate Facility at ANU with additional control for powdery mildew and aphids as required.

\section{Experimental Design}

Plants were randomly allocated on the benchtops in the chambers, following a randomised complete block design with two replicates per genotype. This resulted in a total 200 plots in phase one of the experiment. Because the laboratory phase of estimating $T$ crit was limited to 48 samples per run, a laboratory phase design was created with 6 blocks of 24 units per block, totalling 144 leaf samples. Thus, the laboratory design followed a partially replicated design and was unbalanced with three leaf samples for most genotypes (one sample from chamber replicate one and two samples from chamber replicate two or vice-versa). However, four genotypes were limited to one single leaf sample from each environmental replicate. Due to differences in genotype maturity in the cool and warm environments, samples were collected separately. Genotypes grown in the warm environments were collected prior to those in the cool environments, each being sampled over three consecutive days at 48 samples per day. Like the 2019 field experiment, the design of the controlled environment study, with the initial starting array, was generated using the CyCdesigN package 
(VSN-International Ltd, Hemel Hempstead, UK), and the starting design was optimised for the layout of samples across the 48-well plate using the optimal design (od) package in R (Butler, 2013).

Flag leaf sampling and determination of $T_{\text {crit }}$

Flag leaves were harvested when at least $50 \%$ of the genotypes were at anthesis (Zadoks growth stage 60-69; Zadoks et al., 1974). In the field, leaves were harvested from plants from one of the inner three rows of five-row plots between 0830 and $1030 \mathrm{~h}$. While in the chambers flag leaves of main tillers at anthesis were harvested between 0845 and $1100 \mathrm{~h}$. Immediately after harvesting a flag leaf, a section of approximately 3-4 $\mathrm{cm}$ was cut from the middle. The middle and upper sections of the leaves were kept in resealable bags and dark adapted for between 1.5 and $6 \mathrm{~h}$ prior to estimating $T$ crit (middle section).

Wheat $T$ crit was determined using a custom-built system that combined an imaging fluorometer (FluorCam 800MF, Photon Systems Instrument, Brno, Czech Republic), a thermoregulator attached to the fluorometer (TR2000, Photon Systems Instrument, Brno, Czech Republic) and a 48-well Peltier block. The Peltier block measured $8 \times 12 \mathrm{~cm}$. Each well on the block was $1 \mathrm{~cm}$ in diameter. This set-up was capable of temperature regulation within the $10-70^{\circ} \mathrm{C}$ range with accuracy of $\pm 0.1^{\circ} \mathrm{C}$. Single leaf discs $(\sim 6 \mathrm{~mm})$ were excised from the middle sections of the detached dark-adapted flag leaves and placed on $90 \mu \mathrm{l}$ of tap water in the wells, on the Peltier block. Water was supplied to prevent water stress during the assay. In addition, a transparent glass lid was placed over the Peltier block to reduce evaporative loss during the subsequent application of a heat ramp (i.e. a constant rate of temperature increase). The Peltier block was positioned $14 \mathrm{~cm}$ beneath a CCD (charge-coupled device) camera within the fluorometer for imaging. Leaf discs on the Peltier block were exposed to a temperature ramp at a constant rate of $1^{\circ} \mathrm{C} \mathrm{min}{ }^{-1}$ covering the 20 to $65 \mathrm{degC}$ range. The heat ramp was consistent with generally used measurement protocols (Schreiber and Berry, 1977; Weng and Lai, 2005; Zhu et al., 2018). A simultaneous continuous measurement of the minimum chlorophyll fluorescence $\left(\mathrm{F}_{0}\right)$ of the leaf discs was also done using the imaging fluorometer. Fluorescence was measured by excitation using short flashes $(10 \mu \mathrm{s})$ of extremely weak, blue light. Wheat $T$ crit was determined according to the method of Schreiber and Berry (1977). The FluoroCam 7.0 software package (Photon Systems Instrument, Brno, Czech Republic) was used to pre-process images captured and to export the temperature and fluorescence data files in .txt formats. Wheat $T$ crit was determined from the temperature and data files as the intersection point of two regression lines extrapolated from the flat and steep portion of the temperature dependent $\mathrm{F}_{0}$ response curve (Knight and Ackerly, 2003; O'Sullivan et al., 2017; Schreiber and Berry, 1977) using the packages "segmented" (Muggeo, 2003, 2008, 2016, 2017) and "ggplot2" (Wickham, 2016) in the R statistical environment (R-Core-Team, 2021).

\section{Statistical analysis}

Data analysis was undertaken in three phases: (1) single environment analysis; (2) MET analysis; and (3) correlations of FA model loadings with environmental variables. In the first phase, linear mixed models consisting of fixed, random and residual terms were fitted for each individual environment accounting for the treatment effects and design effects relevant to the different experimental layouts in each environment, using the method of Gilmour et al. (1997) and Cullis et al. (2003). The models for the Dingwall and Barraport West trials covered only the design and spatial effects present in the field. For the Narrabri trial, with a two-phase experimental design spanning both the field and the laboratory, the models accounted for both the field-level design and spatial effects, and the laboratory-level design and spatial effects, including platerows, plate-columns and plate-blocks, as well as day of sampling. In addition, where necessary the models accounted for spatial residual correlation due to neighbouring field plots (field-rows and field-columns), plate positions (plate-columns and plate-rows) and between measurements made on the same plate and day of sampling, when present. Models for the four simulated environments assumed a spatial variability for both the chamber and laboratory phases were not independent. This was due to identical randomisation of the chamber material to the laboratory phase, which made it impossible to separate the chamber spatial variability from well plate spatial variability. Diagnostic plots, such as residuals vs fitted plots, trellis plots of residuals across rows and columns, and variograms were used to check assumptions of normality and homoscedasticity of residuals made during model fitting and to visualise spatial trends along rows and 
columns. Log-likelihood ratio tests were used to test changes in the random spatial effects between models, and Wald tests were used to assess the significance of fixed spatial effects, to select the most parsimonious model for each environment. The selected models were examined for significant genetic effects using Wald tests, with genotype fitted as a fixed term. Environments which showed significant genetic effects for $T$ crit were then incorporated in the second step of the analysis. Broad-sense heritability $\left(\mathrm{H}^{2}\right)$, the proportion of the phenotypic variance attributed to genotype, was estimated following the method of Cullis et al. (2006) for each environment with significant genotypic variation in $T$ crit.

The second phase of the analysis combined data from the environments with significant genetic effects into a MET analysis. Initially, a diagonal variance model was fitted to estimate the GEI effects on $T$ crit, which allowed for heterogeneous genetic variances for each experiment. The diagonal variance model is a baseline model that assumes independence of the GEI effects between environments, and it is analogous to analysing each environment separately. Subsequently, FA models (FA ${ }_{n}$, with $n$ from order 1 to 5; Smith et al., 2001) were fitted to allow for increasing complexity in both the genetic variances and the genetic correlations for the GEI effects. The diagonal variance model and $\mathrm{FA}_{\mathrm{n}}$ models were compared to select a final MET model. Model comparisons involved a holistic assessment of the magnitude of the GEI variation, log-likelihood ratio tests, values of Akaike Information Criterion (AIC; Bozdogan, 1987), the percentage variance accounted for (Beeck et al., 2010; \%VAF; Smith and Cullis, 2018) and changes in heat-maps of the genetic correlations between environments. The preferred/final MET model was used to obtain predictions of the GEI effects via empirical best linear unbiased predictions (eBLUPs), as well as genetic variances for each environment, and genetic correlations between each pair of environments. The genetic correlations indicated the presence or absence of GEI, with high positive correlation between environments corresponding to low GEI (i.e. genotypes have similar rankings in both environments in terms of $T$ crit). Variance parameters were estimated using residual maximum likelihood (REML) estimation (Patterson and Thompson, 1971). To identify superior genotypes (i.e. with consistently high and stable $T$ crit) across environments, measures of overall performance (OP) and stability/sensitivity (defined as root mean square deviation, RMSD) from the factor analytic selection tools (FAST) proposed by Smith and Cullis (2018) were used. Lower RMSD values indicate lower sensitivity

The third phase of the analysis focussed on correlations of FA model loadings with environmental variables. Correlation coefficients between rotated factor loadings from the final FA models and environmental covariates for specified periods preceding anthesis were estimated using Spearman's rank correlations. The environmental covariates were growth air temperature, relative humidity, vapour pressure deficit, photoperiod and solar radiation. Photothermal quotient, the ratio of mean daily incident or intercepted radiation to mean temperature, was also correlated with the rotated factor loadings. Photothermal quotient for the controlled environments was computed using daily light quantity in the chambers - the quantity of photons in the photosynthetic range integrated over the day (daily light integral). These coefficients were used to identify the most likely environmental drivers of $T$ crit GEI.

Analyses were conducted using the ASReml-R software (Butler et al., 2017) within the R statistical environment (R-Core-Team, 2021) and Genstat $\left(21^{\text {st }}\right.$ ed. VSN International Ltd, Hemel Hempstead, UK). ASReml$\mathrm{R}$ estimates variance components of linear mixed models using Residual Maximum Likelihood (REML). In addition to ASReml the R packages, 'ASExtras4' (Butler, 2015), 'myf' (Butler, 2014), and 'reshape2' (Wickham, 2007) were required for analysis and 'ggrepel' (Slowikowski, 2021), 'cluster' (Maechler et al., 2021), and 'ggplot2' (Wickham, 2016) for visualisation of results.

\section{Results}

\section{Conditions of growth environments and single-environment analyses}

The MET dataset comprised five field and four controlled environments. These were used to assess GEI for wheat photosynthetic heat tolerance $(T$ crit $)$ among the 54 genotypes (Table S1). The MET represented a wide range of growth environments in terms of temperature, relative humidity and photoperiod (Table 1). Across the MET, mean sowing to anthesis (when $T$ crit was determined) temperature ranged from 9.9 to $17.1^{\circ} \mathrm{C}$, and average daily maximum temperature at anthesis ranged from 18.8 to $28.1^{\circ} \mathrm{C}$. Mean relative 
humidity was lowest at Narrabri TOS2 (37.5\%) and highest at Barraport West TOS1 (73.1\%). Photoperiod varied almost two-fold between sowing and measurement of $T$ crit at anthesis.

The initial MET dataset comprised 12 thermal environments, but for the final MET analysis, the three environments in Dingwall, Victoria were excluded because of a lack of significant genotypic effects. The models fitted to account for variability in each of the environments included in the final MET analysis can be found in Table S2. The lowest and highest mean $T$ crit were $43.1^{\circ} \mathrm{C}$ (SIM-C2) and $46.4^{\circ} \mathrm{C}$ (Barraport West TOS3), respectively, with variation in $T$ crit across the nine environments ranging from 40.2 to $49.2^{\circ} \mathrm{C}$ (Table 2 ). There were genetic variances (ranging from 0.11 to 0.54 ) and residual variances (ranging from 0.12 to 1.40) between environments. Heritability varied considerably among environments (Table 2 ) being low in the field trials $\left(\mathrm{H}^{2}=0.15-0.25\right)$, and moderate to high in the simulated environments $\left(\mathrm{H}^{2}=0.43-0.75\right.$; Table 2$)$.

\section{Multi-environment trial analysis}

A summary of the diagonal variance and FA models fitted for $T$ crit GEI is presented in Table 3 . The lowest AIC was observed for the $\mathrm{FA}_{1}$ (factor analytic model of order 1) with 76 parameters, which only accounted for $42 \% \mathrm{VAF}$. A marginally higher AIC was observed for the $\mathrm{FA}_{2}$ with 81 parameters, accounting for $56 \% \mathrm{VAF}$. In the absence of a consensus parsimonious model choice based on the AIC and seeking a higher \%VAF, we took a holistic assessment of the magnitude of the GEI and changes in heat-maps of the genetic correlations between environments for REML estimates of $T$ crit. Based on these we chose the $\mathrm{FA}_{2}$ model as our preferred model from which to generate predictions. The $\mathrm{FA}_{2}$ was not significantly different from either the $\mathrm{FA}_{1}$ or $\mathrm{FA}_{5}$ models based on the log-likelihood ratio test (data not shown); however, the $\mathrm{FA}_{2}$ model provided satisfactory fits for most environments, with only Barraport West TOS3 having a \%VAF less than $50 \%$ (Table 4). The first factor $\left(\Lambda_{1}\right)$ of the $\mathrm{FA}_{2}$ model explained $50-86 \%$ of the variance for all environments, except Barraport West TOS3 (0.1\%) and simulated warm season 1 (44.9\%). The first factor loadings were all positive and on a relatively similar scale. However, the $\% \mathrm{VAF}$ by the second factor of the $\mathrm{FA}_{2}$ model for the environment were low $\left(\Lambda_{2}\right.$, mostly less than $\left.20 \%\right)$ and primarily contrasted three of the simulated environments and Barraport West TOS1 with the other five environments (Table 4).

Figure 1 presents a combination of a dendrogram of the dissimilarity matrix and a heat map of the genetic correlation matrix of $T$ crit for the $\mathrm{FA}_{2}$ model. This shows low to high genetic correlations between environments, indicating large GEI. There was little correlation between the warmest environment in Victoria (Barraport West TOS3) and the other environments, suggesting high GEI. By contrast, correlations were higher among the other eight environments - with the highest correlation observed between Narrabri TOS2 and SIM-C1 (Figure 1). The clustering of environments in the dendrogram informed the ordering of environments in the genetic correlation matrix. With Barraport West TOS3 separate, there were two clusters of environments with dissimilarity measures less than 0.43. Cluster 1 comprised the coolest environment in Victoria (Barraport West TOS1) and the two warm simulated environments (SIM-W1 and SIM-W2), and cluster 2 comprised the remaining five environments excluding Barraport TOS3.

\section{Selection of genotypes with consistently high $T_{\text {crit }}$ (performance and stability) across environments}

Genotypes were ranked based on eBLUPs of overall performance (OP) and root mean square deviation (RMSD) - a measure of their sensitivity to changes in environment. The calculation of OP is based on the first factor, while the calculation of RMSD is based on all factors other than the first (Smith and Cullis, 2018), which for our $\mathrm{FA}_{2}$ model is the second factor. Genotypes 75, 173 and 2454 were ranked among the top three in terms of overall performance for $\mathrm{T}_{\text {crit }}$, and had OP scores of $0.64,0.52$ and 0.59 respectively (Fig. 2, Table S3). By contrast, the bottom-ranked three genotypes were 1517, 1752 and 2062 with OP scores of $-0.71,-0.59$, and -0.49 respectively. Only two of the seven commercial cultivars had a better than average OP, of which Ventura had the highest OP, ranking eighth overall with an OP of 0.32. In addition, Ventura was the least sensitive to change in environment (i.e. had the most stable $T$ crit across environments) with an RMSD of 0.01 (Table S3). Apart from Ventura, Suntop was the only commercial cultivar with a better than average OP, ranking $22^{\text {nd }}$ overall, but it was also the second most sensitive genotype to change in environment $(\mathrm{RMSD}=0.275$; Fig. 2 ). These results suggest that there are many genotypes with greater $T$ 
crit but with similar ability to adapt to environmental changes than current commercial cultivars in the germplasm available to Australian wheat breeders. These genotypes could be used to increase genetic gain for photosynthetic heat tolerance.

\section{Correlation of rotated factor loadings with environmental covariates}

The main environmental drivers of $T$ crit GEI were identified through correlations of factor loadings with environmental covariates of interest. Spearman's rank correlations $(\rho)$ were significant for correlations between the first factor loadings and temperature ( $c f \rho=-0.48$ to -0.67 with $r=-0.50$ to -0.82 for $1-30 \mathrm{DBM}$ ), and between the second factor loadings and photoperiod ( $c f \rho=0.59$ to 0.68 with $r=-0.59$ to 0.60 for $1-30$ DBM). There were also significant correlations for vapour pressure deficit, solar radiation and photothermal quotient. The Spearman's rank correlations showed strong correlations between mean temperature, relative humidity and vapour pressure deficit, assessed between sowing and measurement of $T$ crit, with the first factor loadings (Table 5). The directions of correlations between factor loadings and environmental covariates were mostly the same for temperature, vapour pressure deficit, solar radiation and photoperiod, and opposite to that observed for relative humidity (Table 5). These results indicated that all measured environmental variables potentially influenced $T$ crit GEI, and overall mean growth temperature was the most important. When we focused on temperature as the main driver of $T$ crit GEI and analysed correlations for specific times (i.e. daytime, night time, around noon [0900-1500h] or 24-hour [mean daily]), mean daily temperature was, in most cases, the strongest driver of $T$ crit GEI (Table S4).

\section{Discussion}

Wheat breeders aiming to incorporate photosynthetic heat tolerance in their cultivar improvement programmes require critical evaluation of GEI effects on this trait. Our results help address knowledge gaps in wheat $T$ crit GEI. Here we show genetic variance and highly variable heritability for wheat $T$ crit (Table 2 ), as well as significant $T$ crit GEI in Australia (Figure 1, Table 3-4).We identified mean daily growth temperature, especially during the 30 days prior to anthesis, as the most likely environmental driver of $T$ crit GEI (Table 5). We also identified genotypes consistently superior to commercial cultivars in terms of overall performance in $T$ crit (Figure 2, Table S3), thus demonstrating inherent potential in the germplasm available to breeders for developing genotypes with greater photosynthetic heat tolerance.

\section{Genetic variance in wheat photosynthetic heat tolerance}

Plant breeding for increased stress tolerance and productivity requires introduction of new and relevant genetic variation, which is easier to source from elite germplasm pre-adapted to the target environment than from exotic sources (Dwivedi et al., 2016). Most genotypes used in this study were an elite subset of heat tolerant, semi-dwarf germplasm well-adapted to the Australian grain belt. The magnitude of genotypic variation in wheat $T$ crit in the set of genotypes tested reflected the diversity of germplasm sources and breeding histories. Most genotypes either originated from high temperature environments or were selected for heat tolerance under high temperature conditions in Syria, Sudan, Mexico, India, and Australia. In these environments, mean growing season and annual maximum temperatures span $16.3-27.7^{\circ} \mathrm{C}$ and $22.2-36.5^{\circ} \mathrm{C}$, respectively. For wheat, a predominantly temperate crop, these environments and temperatures allowed for identification of elite heat-tolerant germplasm. Genetic variation among some of the genotypes used in this study was introduced by targeted crosses between adapted cultivars and heat tolerant Mexican hexaploid landraces and/or crosses to emmer wheat (T. dicoccon Schrank) - a heat tolerant tetraploid - followed by a backcross to the elite adapted cultivar (see Notes in Table S1). Emmer wheat is the progenitor of most cultivated durum wheat and shows significant variation for heat stress tolerance (Nevo, 2014; Ullah et al., 2018). A recent Australian study (Ullah et al., 2018) examining genetic variability for high-temperature tolerance among hexaploid progenies derived from crosses with emmer wheat, reported that the emmer wheat parents contributed 1-44\% of the genome of the derived lines and that this diversity significantly improved the heat tolerance of the hexaploid materials.

The large genetic variation in wheat $T$ critreported in this paper indicates that significant intraspecies variation in wheat $T$ crit exists, and can be exploited in breeding. Similar to ectotherms and non-crop plants, 
this intraspecies variation in heat tolerance might buffer heat stress via increased thermal safety margins (Araújo et al., 2013; Herrando-Pérez et al., 2019; O'Sullivan et al., 2017; Sunday et al., 2011). Our results show a gradient (i.e. intraspecies variation) in $T$ crit across the 54 wheat genotypes (Figure 2). Some genotypes (e.g. 75, 173, and 2454) could be categorised as high $T$ critwhile others such as genotypes 2062, 1752 and 1517 as low $T$ crit relative to the commercial cultivars. That some genotypes had a consistently higher and stable $T$ crit compared to most of the commercial cultivars used in this study indicates potential for significant genetic gains in genotypic heat tolerance.

The general understanding of interspecific gradient in photosynthetic heat tolerance and links between $T$ crit and environmental temperature is mostly shaped by data from interspecific studies of non-crop plants and mostly woody species (Lancaster and Humphreys, 2020; O'Sullivan et al., 2017; Zhu et al., 2018). For example, the assumption that higher heat tolerance promotes fitness/performance in hotter environments (Araújo et al., 2013). Interestingly, some recent studies do not support this assumption. Perez and Feeley (2020) indicated that species with higher photosynthetic heat tolerances could be more vulnerable to heat stress because of their hotter leaf temperatures and narrower thermal safety margins. Vulnerability is likely related to inhibition of the dark reaction phase of photosynthesis and the export of sugars from leaves. Nevertheless, when knowledge of $T$ crit is used for supporting wheat crop improvement, then understanding responses of intraspecies variation in wheat $T$ crit to stress and the molecular mechanism of intraspecies variation in wheat $T$ crit would be more useful than interspecies variation. This is particularly the case when considering the large amount of genetic divergence between wheat and the mostly woody species that have been the focus of photosynthetic heat tolerance research. In addition, understanding the biological implications of intraspecific variation in $T$ crit could be integrated into models to improve projection reliability of climate change impacts on crop production (Pacifici et al., 2015). We note that our system of determining $T$ crit, although high-throughput, was limited to detached leaf discs, hours after detachment, and did not allow for whole-plant measurement. The $T$ crit of detached leaves may not always reflect in situ levels of photosynthetic heat tolerance (Buchner et al., 2013, 2017) and our estimates of $T$ crit may thus be conservative.

The experimental field sites for this study were chosen as representative of Australian wheat production practices and environments. We did not detect significant genetic effects on wheat $T$ crit among 20 genotypes in any of the three environments at Dingwall, Victoria. Consequently, these environments were excluded from the MET analysis. It is unclear why genetic effects were not detectable in Dingwall but were present in Barraport West and the other environments where the same set of 20 genotypes were also studied. The sites in Dingwall and Barraport West are only $49 \mathrm{~km}$ apart; both are in the Mallee district of the SE region of Australia (i.e. have similar climate); and both have relatively infertile soils (Isbell, 2002). The differences in responses of the 20 genotypes between Dingwall and Barraport West, or even Narrabri, New South Wales suggest a strong environmental and/or management influence on wheat $T$ crit. This could have been due to physiological adaptations to microhabitat and leaf temperature regulation (Curtis et al., 2019; Perez and Feeley, 2020) in response to rainfall and irrigation (timing, amount and form of application). The field trials were primarily rainfed, with supplemental watering provided by an overhead centre pivot (Dingwall) or overhead lateral move (Barraport West and Narrabri) irrigator. While the total amount of water supplied at Dingwall was lower than Barraport West, both sites received adequate irrigation, and yield of the Dingwall trial was consistently higher than Barraport West (Coast et al., 2021).

\section{Heritability of wheat photosynthetic heat tolerance was highly variable}

Heritability is essential for the selection of superior genotypes, and identification of genomic loci with an effect on the trait of interest. High $\mathrm{H}^{2}$ indicates that most of the observed phenotypic variation is attributed to genotype and therefore response to selection will be high. We observed highly variable broad-sense heritability for wheat $T$ crit, from a low of 0.15 to a high of 0.75 , with clear differences between the field $\left(\mathrm{low}^{2}\right)$ and the controlled environments (medium to high $\mathrm{H}^{2}$; Table 2). The differences in $\mathrm{H}^{2}$ between environments reflect the larger residual variances in the field environments compared to the controlled environments. Heritability of wheat photosynthetic heat tolerance was comparable to $\mathrm{H}^{2}$ reported for leaf cellular membrane stability, a different measure of leaf heat tolerance, where values ranged from 0.09 to 0.74 in a variety of crops including 
soyabean (Glycine max L.; $\mathrm{H}^{2}=0.09-0.65$; Martineau et al., 1979), maize (Zea mays L.; $\mathrm{H}^{2}=0.58$; Ottaviano et al., 1991) and spring wheat $\left(\mathrm{H}^{2}=0.74\right.$; Blum et al., 2001). The range of $T$ crit $\mathrm{H}^{2}$ in our study is larger than the $\mathrm{H}^{2}$ previously reported for wheat flag leaf photosynthesis in Australia (0.45-0.65; Silva-Pérez et al., 2020), Mexico (0.33-0.50; Molero and Reynolds, 2020), and in the United Kingdom (0.50-0.59; Carmo-Silva et al., 2017; Driever et al., 2014). The fact that the range in $\mathrm{H}^{2}$ for $T$ crit is larger than in other related traits may be due, in part, to our use of the sound experimental practice of multi-phase experimental design for the $T$ crit experiment. This sound design, together with the advanced statistical analysis techniques, improved the accuracy of genotype comparison by accounting for extraneous sources of trend in the field and laboratory experiments.

The high $T_{\text {crit }} \mathrm{H}^{2}$ observed in some of our environments suggest that sustainable genetic gains could be achieved by including $T$ crit as a selection criterion in wheat breeding. Availability of high throughput phenotyping tools for $T$ crit including the one used in this study or reported in Arnold et al. (2021) would make inclusion of $T$ crit in breeding easier. Indirect selection for higher grain yield through secondary traits with higher heritability and strong associations with grain yield can be more effective than direct selection for grain yield under stress (Bänziger and Lafitte, 1997). However, the association between $T$ crit and grain yield has not been established. Whilst many recent reports assume links between photosynthetic heat tolerance and increased plant fitness under heat stress (Ferguson et al., 2020; Leon-Garcia and Lasso, 2019; Perez and Feeley, 2020; Zhu et al., 2018), there remains a need to validate this relationship more thoroughly. Such studies would ascertain whether or not higher $T$ crit translates to better grain yield and quality under heat stress, and whether higher $T$ crit bears any yield or quality penalty in non-stressed environments. In particular, there is compelling evidence that reproductive organs, including floral organs and developing seeds, are more vulnerable than leaves to heat and drought stresses (Ruan, 2014). This susceptibility can be due to poor sink capacity, independent of photosynthesis, as shown in tomato (Li et al., 2011).

Multi-environment trial analysis using factor analytic models showed significant GEI effects on $T_{\text {crit }}$

Genetic gains in heat tolerance might be achieved by incorporating photosynthetic heat tolerance traits in current breeding programmes, but this would require a critical assessment of photosynthetic heat tolerance GEI. The FA model provided an efficient and realistic way to model the complexity of both the genetic variances and the genetic correlations for wheat $T$ crit GEI effects (Smith and Cullis, 2018; Smith et al., 2001, 2015). Additionally, the flexibility of the linear mixed model in dealing with unbalanced data enabled analysis of the MET data with varying numbers of genotypes (20-50) and replications (2-4) across experiments. Our final FA model accounted for $>50 \%$ of the genotypic variance in most environments and up to $100 \%$ in three of the nine environments (Table 4). The total variance accounted for across all environments was relatively low and constrained by the poor fit for $T$ crit in Barraport West TOS3.

Factor analytic models have also been used to define mega-environments in plant breeding programmes (Smith and Cullis, 2018; Smith et al., 2015). Based on the genetic correlations from our final FA model, all environments (excluding Barraport West TOS3) clustered into two groups (or mega-environments) suggesting strong GEI between these two groups, and weaker GEI within each group. Barraport West TOS3 shared particularly low genetic correlations with the other eight environments (Figure 1). By contrast, the high mean genetic correlations for $T$ crit between environments within each of clusters 1 and 2 suggested similar genetic responses for environments (i.e. low GEI) within a cluster. Narrabri TOS2 was closely correlated with the two simulated cool seasons, especially simulated cool season 1 (Figure 1). From a phenotyping perspective, these environments with strong correlations indicate that the APPF Growth Capsules could be used in lieu of some of the field environments to evaluate wheat $T$ crit.

Our study sets a sound framework for supporting wheat breeding using photosynthetic heat tolerance in Australia. However, it is a single study of a single trait, and thus the application to overall heat tolerance improvement is limited as other traits also contribute to heat tolerance. For greater impact, $T$ crit GEI should be considered alongside other relevant energy-related physiological traits. For example, our recent works showed stronger response of wheat mitochondrial respiration in the dark $\left(\mathrm{O}_{2}\right.$ consumption basis, $R$ dark $\left.-\mathrm{O}_{2}\right)$ to high temperature stress than photosynthesis, and greater $R$ dark $-\mathrm{O}_{2}$ response to night than 
day warming (Coast et al., 2021; Posch et al., 2021). Under warm nights wheat biomass fell in association with decline in $R$ dark $-\mathrm{O}_{2}$ and increased alternative oxidase pathway capacity, suggesting a reduction in plant energy demand under warm nights. The strong links of biomass decline under heat stress with photosynthesis and respiration strengthens the case for exploiting a combination of respiratory heat tolerance traits (e.g. $T$ max of $R$ dark , the temperature where $R$ dark is maximal and beyond which respiratory function rapidly declines) and $T$ crit for cultivar improvement.

\section{Wheat $T_{\text {crit }}$ at anthesis is strongly influenced by mean daily growth temperature preceding anthesis}

Our results show the $T$ crit of PSII in wheat flag leaves was influenced by all measured environmental covariates. However, mean daily temperature correlated best or second best with first factor loadings for all periods, except three days prior to anthesis. Growth temperature is one of the most influential environmental drivers of photosynthesis (Atkin and Tjoelker, 2003; Hikosaka et al., 2005; Wright et al., 2006) and within the photosynthetic machinery, the thylakoid membrane-embedded photosystem II (PSII) is particularly heatsensitive (Armond et al., 1978). High temperature blocks the PSII reaction centre and dissociates antennae pigment protein complexes from the central core of the PSII light harvesting apparatus. These defects lead to decreased quantum yield of electron transport and a loss of electron transport activity. That mean daily temperature was correlated with $T$ crit in the short (1 day prior to anthesis), medium (7-30 days prior to anthesis), and long (sowing to anthesis) terms likely reflects different scales of mechanistic adjustments in the leaf. Adjustments due to temperature stress in the short term may be underpinned by biochemical changes, such as increased relative abundance of saturated fatty acids (Zhu et al., 2018), expression of heat shock proteins (Vierling, 1991) and/or changes in the concentration of key metabolites (Kaplan et al., 2004). These changes could provide temporary protection to PSII embedded in the lipid bilayer of the thylakoid membrane. On the other hand, the medium- and/or long-term associations presumably relate to adaptations of thylakoid membranal and leaf functional traits which require greater investment to provide better protection or effect repairs to PSII. Such investments in membranal characteristics may be related to repairs of PSII, e.g. curvature, thickness, and stromal gaps (Theis and Schroda, 2016; Yoshioka-Nishimura, 2016), as well as leaf structural and morphological traits (e.g. higher leaf mass per area, leaf thickness and density) that confer high temperature tolerance. Species with higher leaf mass per area have higher photosynthetic heat tolerance (Sastry and Barua, 2017; Wright et al., 2005).

In addition to links between $T$ crit and environmental covariates that span various days prior to measurement of $T$ crit, we specifically investigated links between $T$ crit and growth temperatures of specific time frames (i.e. daytime, nighttime, midday and $24 \mathrm{~h}$ ). $T$ crit was mostly dependent upon mean daily temperature. We

had expected a stronger link between $T$ crit and the higher temperatures around midday. However, in the Australian context, the strong relationship between mean daily temperature and $T$ crit was still notable, given wheat yield losses have been attributed to a combination of increasing mean daily temperatures and heatwaves (Ababaei and Chenu, 2020).

\section{Conclusion}

Genetic variance for $T$ crit in a subset of the Australian wheat breeding germplasm points to potenitial for significant genetic gains in heat tolerance. Our results - showing significant $T$ crit GEI, and mean daily growth temperature prior to anthesis as the major environmental driver of $T$ crit GEI - support the development of high temperature tolerant wheat. The potential gains of incorporating $T$ crit in breeding programmes is worth exploring even though heritability for $T_{\text {crit }}$ in the field was relatively low. Links between wheat $T$ crit and crop performance should be investigated further to ascertain whether or not higher $T$ crit translates to better grain yield and quality under heat stress, and whether higher $T$ crit bears any yield or quality penalty in non-stressed environments.

\section{Acknowledgements}

We acknowledge and celebrate the First Australians on whose traditional lands this research was undertaken, and pay our respect to the elders past and present. This work was supported by grants from the ARC Centre of Excellence in Plant Energy Biology (CE140100008), and the Australian Grains Research and 
Development Corporation (GRDC) Postdoctoral Fellowship: "Photosynthetic Acclimation to High Temperature in Wheat" (US1904-003RTX - 9177346) and National Wheat Heat Tolerance Project (US00080). Onoriode Coast received support from Research England's 'Expanding Excellence in England' (E3)-funded Food and Nutrition Security Initiative of the Natural Resources Institute, University of Greenwich. Bradley C. Posch was supported by the Australian Government Research Training Program. We are grateful to the Australian Plant Phenomics Facility (APPF) for use of their growth capsules. The APPF is supported under the National Collaborative Research Infrastructure Strategy of the Australian Government. We thank Dr Richard Poire-Lassus for managing the growth capsules. We also thank Amy Smith of Birchip Cropping Group, Victoria, for help with field trials in Victoria, and Sabina Yasmin for managing the trial at Narrabri. We are grateful to the farmers who generously provided us with field sites for the 2017 and 2018 trials. Staff of the ANU Research School of Biology Plant Services team, especially Christine Larsen, Jenny Rath, Gavin Pritchard and Steven Dempsey are thanked for maintaining the plants in the controlled environments.

\section{CONFLICT OF INTEREST}

The authors declare no conflict of interest.

\section{References}

Ababaei, B., and Chenu, K. (2020). Heat shocks increasingly impede grain filling but have little effect on grain setting across the Australian wheatbelt. Agricultural and Forest Meteorology 284, 107889.

ABARES Agricultural Commodity Statistics (2021) Australian Bureau of Agricultural and Resource Economics and Sciences, Canberra, Australia. Available at: https://www.agriculture.gov.au/abares/researchtopics/agricultural-outlook/data\#2020 [Accessed on 21 August 2021]

Araújo, M. B., Ferri-Yanez, F., Bozinovic, F., Marquet, P. A., Valladares, F., and Chown, S. L. (2013). Heat freezes niche evolution. Ecology letters 16, 1206-1219.

Armond, P. A., Schreiber, U., and Bjorkman, O. (1978). Photosynthetic acclimation to temperature in the desert shrub, Larrea divaricata : II. Light-harvesting efficiency and electron transport.Plant Physiology 61 , 411-415.

Arnold, P. A., Briceno, V. F., Gowland, K. M., Catling, A. A., Bravo, L. A., and Nicotra, A. B. (2021). A high-throughput method for measuring critical thermal limits of leaves by chlorophyll imaging fluorescence.Functional Plant Biology 48 , 634-646.

Asseng, S., Cammarano, D., Basso, B., Chung, U., Alderman, P. D., Sonder, K., Reynolds, M., and Lobell, D. B. (2017). Hot spots of wheat yield decline with rising temperatures. Global Change Biology23, 2464-2472.

Asseng, S., Ewert, F., Martre, P., Rotter, R. P., Lobell, D. B., Cammarano, D., Kimball, B. A., Ottman, M. J., Wall, G., and White, J. W. (2015). Rising temperatures reduce global wheat production. Nature Climate Change 5, 143-147.

Atkin, O. K., and Tjoelker, M. G. (2003). Thermal acclimation and the dynamic response of plant respiration to temperature. Trends in Plant Science 8 , 343-351.

Azam, F. I., Chang, X., and Jing, R. (2015). Mapping QTL for chlorophyll fluorescence kinetics parameters at seedling stage as indicators of heat tolerance in wheat. Euphytica $202,245-258$.

Banziger, M., and Lafitte, H. (1997). Efficiency of secondary traits for improving maize for low-nitrogen target environments. Crop Science $37,1110-1117$.

Beeck, C. P., Cowling, W. A., Smith, A. B., and Cullis, B. R. (2010). Analysis of yield and oil from a series of canola breeding trials. Part I. Fitting factor analytic mixed models with pedigree information. Genome 53, 992-1001.

Berry, J., and Bjorkman, O. (1980). Photosynthetic response and adaptation to temperature in higher-plants. Annual Review of Plant Physiology and Plant Molecular Biology 31 , 491-543. 
Blum, A., Klueva, N., and Nguyen, H. T. (2001). Wheat cellular thermotolerance is related to yield under heat stress. Euphytica 117, 117-123.

BOM and CSIRO. State of the climate. 2020. Available at: http://www.bom.gov.au/state-of-theclimate/documents/State-of-the-Climate-2020.pdf [Accessed on 21 August 2021].

Bozdogan, H. (1987). Model selection and Akaike's Information Criterion (AIC): The general theory and its analytical extensions.Psychometrika $\mathbf{5 2}, 345-370$.

Brien, C. J., and Bailey, R. A. (2006). Multiple randomizations. Journal of the Royal Statistical Society: Series B (Statistical Methodology) 68, 571-609.

Buchner, O., Karadar, M., Bauer, I., and Nuener, G. 2013. A novel system for in situ determination of heat tolerance of plants: first results on alpine dwarf shrubs. Plant Methods $\mathbf{9}, 7$.

Buchner, O., Roach, T., Gertzen, J., Schenk, S., Karadar, M., Stoggl, W., Miller, R., Bertel, C., Neuner, G., and Kranner, I. (2017). Drought affects the heat-hardening capacity of alpine plants as indicated by changes in xanthophyll cycle pigments, singlet oxygen scavenging, $\alpha$-tocopherol and plant hormones. Environmental and Experimental Botany 133, 159-175.

Butler, D. (2014). myf: Utility functions for asreml objects.. R package version 1.0.

Butler, D. (2015). ASExtras4: Utility functions for asreml objects. R package version 1.0.

Butler, D. G. (2013). On the Optimal Design of Experiments under the Linear Mixed Model., The University of Queensland, Australia.

Butler, D. G., Cullis, B. R., Gilmour, A. R., Gogel, B. G., and Thompson, R. (2017). ASReml-R Reference Manual Version 4. VSN International Ltd, Hemel Hempstead, United Kingdom.

Carmo-Silva, E., Andralojc, P., Scales, J., Driever, S., Mead, A., Lawson, T., Raines, C., and Parry, M. (2017). Phenotyping of field-grown wheat in the UK highlights contribution of light response of photosynthesis and flag leaf longevity to grain yield. Journal of Experimental Botany 68 , 3473-3486.

Climate Change Australia (2021) Climate change in Australia: Climate information, projections, tools and data. Available at: https://www.climatechangeinaustralia.gov.au/en/ [Accessed on 21 August 2021]

Coast, O., Posch, B. C., Bramley, H., Gaju, O., Richards, R. A., Lu, M., Ruan, Y.-L., Trethowan, R., and Atkin, O. K. (2021). Acclimation of leaf photosynthesis and respiration to warming in field-grown wheat.Plant, Cell \& Environment $44,2331-2346$.

Comstock, R. (1977). Quantitative genetics and the design of breeding programs. In : Proceedings of the International Conference on Quantitative Genetics, pp. 1705-1718. Iowa State University Press. Ames, USA.

Cullis, B. R., Smith, A. B., and Coombes, N. E. (2006). On the design of early generation variety trials with correlated data. Journal of Agricultural, Biological, and Environmental Statistics 11, 381-393.

Cullis, B. R., Smith, A. B., Panozzo, J. F., and Lim, P. (2003). Barley malting quality: are we selecting the best? Australian Journal of Agricultural Research 54, 1261-1275.

Curnow, R. (1959). The analysis of a two phase experiment.Biometrics 15 , 60-73.

Curtis, E. M., Knight, C. A., and Leigh, A. (2019). Intracanopy adjustment of leaf-level thermal tolerance is associated with microclimatic variation across the canopy of a desert tree (Acacia papyrocarpa). Oecologia $189,37-46$.

Dreccer, M. F., Condon, A. G., Macdonald, B., Rebetzke, G. J., Awasi, M.-A., Borgognone, M. G., Peake, A., Piñera-Chavez, F. J., Hundt, A., Jackway, P., and McIntyre, C. L. (2020). Genotypic variation for lodging 
tolerance in spring wheat: wider and deeper root plates, a feature of low lodging, high yielding germplasm. Field Crops Research 258, 107942.

Driever, S., Lawson, T., Andralojc, P., Raines, C., and Parry, M. (2014). Natural variation in photosynthetic capacity, growth, and yield in 64 field-grown wheat genotypes. Journal of Experimental Botany65 , 49594973.

Dwivedi, S., Ceccarelli, S., Blair, M., Upadhyaya, H., Are, A., and Ortiz, R. (2016). Landrace germplasm for improving yield and abiotic stress adaptation. Trends in Plant Science 21,31-42.

Ferguson, J. N., McAusland, L., Smith, K. E., Price, A. H., Wilson, Z. A., and Murchie, E. H. (2020). Rapid temperature responses of photosystem II efficiency forecast genotypic variation in rice vegetative heat tolerance. The Plant Journal 104, 839-855.

Geange, S. R., Arnold, P. A., Catling, A. A., Coast, O., Cook, A. M., Gowland, K. M., Leigh, A., Notarnicola, R. F., Posch, B. C., and Venn, S. E. (2020). The thermal tolerance of photosynthetic tissues: a global systematic review and agenda for future research. New Phytologist229 , 2479-2513.

Gilmour, A. R., Cullis, B. R., and Verbyla, A. P. (1997). Accounting for natural and extraneous variation in the analysis of field experiments. Journal of Agricultural, Biological, and Environmental Statistics2, 269-293.

GRDC - Grains Research \& Development Corporation (2018) Research, Development and Extension Plan 2018-2023: KIT 1.1 Minimise the impact of high temperature at flowering and grain fill on grain yield and stability. Available at: https://rdeplan.grdc.com.au/__data/assets/pdf_file/0020/434090/KIT-1.1_detailed-strategy.pdf [Sourced on 12 September 2021]

Herrando-Pérez, S., Ferri-Yáñez, F., Monasterio, C., Beukema, W., Gomes, V., Belliure, J., Chown, S. L., Vieites, D. R., and Araújo, M. B. (2019). Intraspecific variation in lizard heat tolerance alters estimates of climate impact. Journal of Animal Ecology88 , 247-257.

Hikosaka, K., Ishikawa, K., Borjigidai, A., Muller, O., and Onoda, Y. (2005). Temperature acclimation of photosynthesis: mechanisms involved in the changes in temperature dependence of photosynthetic rate. Journal of Experimental Botany 57, 291-302.

Hüve, K., Bichele, I., Tobias, M., and Niinemets, Ü. (2006). Heat sensitivity of photosynthetic electron transport varies during the day due to changes in sugars and osmotic potential. Plant, Cell $\&$ Environment $29,212-228$.

Isbell, R. F. (2002). The Australian Soil Classification, Revised Ed. CSIRO Publishing, Collingwood, Victoria, Australia.

Kaplan, F., Kopka, J., Haskell, D. W., Zhao, W., Schiller, K. C., Gatzke, N., Sung, D. Y., and Guy, C. L. (2004). Exploring the temperature-stress metabolome of Arabidopsis. Plant Physiology136 , 4159-4168.

Knight, C. A., and Ackerly, D. D. (2002). An ecological and evolutionary analysis of photosynthetic thermotolerance using the temperature-dependent increase in fluorescence. Oecologia130, 505-514.

Knight, C. A., and Ackerly, D. D. (2003). Evolution and plasticity of photosynthetic thermal tolerance, specific leaf area and leaf size: congeneric species from desert and coastal environments. New Phytologist $160,337-347$.

Lancaster, L. T., and Humphreys, A. M. (2020). Global variation in the thermal tolerances of plants. Proceedings of the National Academy of Sciences of the United States of America 117, 13580-13587.

Leon-Garcia, I. V., and Lasso, E. (2019). High heat tolerance in plants from the Andean highlands: Implications for paramos in a warmer world.PLOS ONE 14, e0224218.

Li, Z., Palmer, W. M., Martin, A. P., Wang, R., Rainsford, F., Jin, Y., Patrick, J. W., Yang, Y., and Ruan, Y.-L. (2011). High invertase activity in tomato reproductive organs correlates with enhanced sucrose import 
into, and heat tolerance of, young fruit. Journal of Experimental Botany 63, 1155-1166.

Lin, Y.-S. (2012). How will Eucalyptus tree species respond to global climate change?: A comparison of temperature responses of photosynthesis, University of Western Sydney.

Maechler, M., Rousseeuw, P., Struyf, A., Hubert, M., and Hornik, K. (2021). Cluster: Cluster Analysis Basics and Extensions. R package version 2.1.2.

Marias, D. E., Meinzer, F. C., and Still, C. (2017). Leaf age and methodology impact assessments of thermotolerance of Coffea arabica. Trees 31, 1091-1099.

Martineau, J. R., Williams, J. H., and Specht, J. E. (1979). Temperature tolerance in soybeans. II. Evaluation of segregating populations for membrane thermostability.Crop Science 19 , 79-81.

Maxwell, K., and Johnson, G. N. (2000). Chlorophyll fluorescence - a practical guide. Journal of Experimental Botany 51, 659-668.

Molero, G., and Reynolds, M. P. (2020). Spike photosynthesis measured at high throughput indicates genetic variation independent of flag leaf photosynthesis. Field Crops Research 255 , 107866.

Muggeo, V. M. R. (2003). Estimating regression models with unknown break-points. Statistics in Medicine $22,3055-3071$.

Muggeo, V. M. R. (2008). Segmented: an R package to fit regression models with broken-line relationships. $R$ News $\mathbf{8}, 20-25$.

Muggeo, V. M. R. (2016). Testing with a nuisance parameter present only under the alternative: a scorebased approach with application to segmented modelling. Journal of Statistical Computation and Simulation $86,3059-3067$.

Muggeo, V. M. R. (2017). Interval estimation for the breakpoint in segmented regression: a smoothed scorebased approach. Australian \& New Zealand Journal of Statistics 59, 311-322.

Nevo, E. (2014). Evolution of wild emmer wheat and crop improvement. Journal of Systematics and Evolution 52, 673-696.

O'Sullivan, O. S., Heskel, M. A., Reich, P. B., Tjoelker, M. G., Weerasinghe, L. K., Penillard, A., Zhu, L., Egerton, J. J., Bloomfield, K. J., Creek, D., Bahar, N. H., Griffin, K. L., Hurry, V., Meir, P., Turnbull, M. H., and Atkin, O. K. (2017). Thermal limits of leaf metabolism across biomes. Global Change Biology 23 , 209-223.

Oliveira, I. C. M., Guilhen, J. H. S., de Oliveira Ribeiro, P. C., Gezan, S. A., Schaffert, R. E., Simeone, M. L. F., Damasceno, C. M. B., de Souza Carneiro, J. E., Carneiro, P. C. S., and da Costa Parrella, R. A. (2020). Genotype-by-environment interaction and yield stability analysis of biomass sorghum hybrids using factor analytic models and environmental covariates. Field Crops Research 257 , 107929.

Ottaviano, E., Sari Gorla, M., Pè, E., and Frova, C. (1991). Molecular markers (RFLPs and HSPs) for the genetic dissection of thermotolerance in maize. Theoretical and Applied Genetics 81, 713-719.

Pacifici, M., Foden, W. B., Visconti, P., Watson, J. E. M., Butchart, S. H. M., Kovacs, K. M., Scheffers, B. R., Hole, D. G., Martin, T. G., Akçakaya, H. R., Corlett, R. T., Huntley, B., Bickford, D., Carr, J. A., Hoffmann, A. A., Midgley, G. F., Pearce-Kelly, P., Pearson, R. G., Williams, S. E., Willis, S. G., Young, B., and Rondinini, C. (2015). Assessing species vulnerability to climate change. Nature Climate Change $\mathbf{5}$, 215-224.

Patterson, H. D., and Thompson, R. (1971). Recovery of inter-block information when block sizes are unequal. Biometrika $58,545-554$.

Perez, T. M., and Feeley, K. J. (2020). Photosynthetic heat tolerances and extreme leaf temperatures. Functional Ecology 34, 2236-2245. 
Posch, B. C., Zhai, D., Coast, O., Scafaro, A. P., Bramley, H., Reich, P. B., Ruan, Y-L., Trethowan, R., Way, D. A., and Atkin, O. K. (2021). Wheat respiratory $\mathrm{O}_{2}$ consumption falls with night warming alongside greater respiratory $\mathrm{CO}_{2}$ loss and reduced biomass. Journal of Experimental Botany. Accepted subject to minor revision

Qureshi, M. E., Hanjra, M. A., and Ward, J. (2013). Impact of water scarcity in Australia on global food security in an era of climate change. Food Policy 38, 136-145.

R-Core-Team (2021). R: A language and environment for statistical computing. R Foundation for Statistical Computing, Vienna, Austria. URL

Rekika, D., Monneveux, P., and Havaux, M. (1997). The in vivotolerance of photosynthetic membranes to high and low temperatures in cultivated and wild wheats of the Triticum and Aegilopsgenera. Journal of Plant Physiology 150, 734-738.

Ruan, Y.-L. (2014). Sucrose metabolism: Gateway to diverse carbon use and sugar signaling. Annual Review of Plant Biology 65, 33-67.

Sae-Lim, P., Komen, H., Kause, A., and Mulder, H. A. (2014). Identifying environmental variables explaining genotype-by-environment interaction for body weight of rainbow trout (Onchorynchus mykiss): reaction norm and factor analytic models. Genetics Selection Evolution46 , 16.

Sastry, A., and Barua, D. (2017). Leaf thermotolerance in tropical trees from a seasonally dry climate varies along the slow-fast resource acquisition spectrum. Scientific Reports 7 , 11246.

Schreiber, U., and Berry, J. A. (1977). Heat-induced changes of chlorophyll fluorescence in intact leaves correlated with damage of the photosynthetic apparatus. Planta 136 , 233-238.

Schwarz, G. (1978). Estimating the dimension of a model. The Annals of Statistics 6 , 461-464.

Sharma, D. K., Andersen, S. B., Ottosen, C.-O., and Rosenqvist, E. (2012). Phenotyping of wheat cultivars for heat tolerance using chlorophyll a fluorescence. Functional Plant Biology 39 , 936-947.

Sharma, D. K., Torp, A. M., Rosenqvist, E., Ottosen, C.-O., and Andersen, S. B. (2017). QTLs and potential candidate genes for heat stress tolerance identified from the mapping populations specifically segregating for $\mathrm{F}_{\mathrm{v}} / \mathrm{F}_{\mathrm{m}}$ in wheat.Frontiers in Plant Science $\mathbf{8}, 1668$.

Silva-Pérez, V., De Faveri, J., Molero, G., Deery, D. M., Condon, A. G., Reynolds, M. P., Evans, J. R., and Furbank, R. T. (2020). Genetic variation for photosynthetic capacity and efficiency in spring wheat. Journal of Experimental Botany $\mathbf{7 1}$, 2299-2311.

Slowikowski, K. (2021). ggrepel: Automatically position non-overlapping text labels with 'ggplot2'. R package version 0.9.1. https://CRAN.R-project.org/package=ggrepel.

Smith, A., Cullis, B., and Thompson, R. (2001). Analyzing variety by environment data using multiplicative mixed models and adjustments for spatial field trend. Biometrics 57, 1138-1147.

Smith, A. B., and Cullis, B. R. (2018). Plant breeding selection tools built on factor analytic mixed models for multi-environment trial data.Euphytica 214, 143.

Smith, A. B., Ganesalingam, A., Kuchel, H., and Cullis, B. R. (2015). Factor analytic mixed models for the provision of grower information from national crop variety testing programs. Theoretical and Applied Genetics 128 , 55-72.

Sunday, J. M., Bates, A. E., and Dulvy, N. K. (2011). Global analysis of thermal tolerance and latitude in ectotherms. Proceedings of the Royal Society B: Biological Sciences 278 , 1823-1830.

Theis, J., and Schroda, M. (2016). Revisiting the photosystem II repair cycle. Plant Signaling 85 Behavior 11, e1218587. 
Thomas, J. B., Voskuil, W., Olsman, H., and de, B. H. (1962). Fluorescence-induction phenomena in isolated chloroplasts.Biochimica et Biophysica Acta 59, 224-226.

Trethowan, R., Chatrath, R., Tiwari, R., Kumar, S., Saharan, M. S., Bains, N., Sohu, V. S., Srivastava, P., Sharma, A., De, N., Prakash, S., Singh, G. P., Sharma, I., Eagles, H., Diffey, S., Bansal, U., and Bariana, H. (2018). An analysis of wheat yield and adaptation in India.Field Crops Research 219 , 192-213.

Ullah, S., Bramley, H., Daetwyler, H. D., He, S., Thistlethwaite, R., and Trethowan, R. (2018). Genetic variation in emmer wheat (Triticum dicoccon Schrank) improves the heat tolerance of bread wheat. Frontiers in Plant Science $\mathbf{9}, 1529$.

Vierling, E. (1991). The roles of heat shock proteins in plants. Annual Review of Plant Physiology and Plant Molecular Biology42, 579-620.

Weng, J.-H., and Lai, M.-F. (2005). Estimating heat tolerance among plant species by two chlorophyll fluorescence parameters.Photosynthetica $43,439-444$.

Wickham, H. (2007). Reshaping Data with the reshape Package.Journal of Statistical Software 21 , 1-20.

Wickham, H. (2016). ggplot2: Elegant Graphics for Data Analysis. 2nd/Ed. Springer-Verlag, New York.

Wright, I. J., Reich, P. B., Atkin, O. K., Lusk, C. H., Tjoelker, M. G., and Westoby, M. (2006). Irradiance, temperature and rainfall influence leaf dark respiration in woody plants: evidence from comparisons across 20 sites. New Phytologist 169 , 309-319.

Wright, I. J., Reich, P. B., Cornelissen, J. H. C., Falster, D. S., Garnier, E., Hikosaka, K., Lamont, B. B., Lee, W., Oleksyn, J., Osada, N., Poorter, H., Villar, R., Warton, D. I., and Westoby, M. (2005). Assessing the generality of global leaf trait relationships. New Phytologist 166 , 485-496.

Yoshioka-Nishimura, M. (2016). Close relationships between the PSII repair cycle and thylakoid membrane dynamics. Plant and Cell Physiology 57 , 1115-1122.

Zadoks, J. C., Chang, T. T., and Konzak, C. F. (1974). A decimal code for the growth stages of cereals. Weed Research 14, 415-421.

Zhao, C., Liu, B., Piao, S., Wang, X., Lobell, D. B., Huang, Y., Huang, M., Yao, Y., Bassu, S., and Ciais, P. (2017). Temperature increase reduces global yields of major crops in four independent estimates.Proceedings of the National Academy of Sciences of the United States of America 114, 9326-9331.

Zhu, L., Bloomfield, K. J., Hocart, C. H., Egerton, J. J. G., O'Sullivan, O. S., Penillard, A., Weerasinghe, L. K., and Atkin, O. K. (2018). Plasticity of photosynthetic heat tolerance in plants adapted to thermally contrasting biomes. Plant, Cell \& Environment41, 1251-1262.

Tables

Table 1. Growing period and growth conditions for each environment included in the multi-environment trial analysis of wheat $T$ crit.

\begin{tabular}{llll}
\hline Environment $^{1}$ & Environment ID & Growing period (sowing to anthesis) & Growing period (sowing to anthes \\
\hline & & & Mean temperature $\left({ }^{\circ} \mathrm{C}\right)$ \\
Barraport West, VIC TOS1 & VIC-TOS1 & 09 May - 05 October 2018 & 9.9 \\
Barraport West, VIC TOS2 & VIC-TOS2 & 01 June - 19 October 2018 & 10.4 \\
Barraport West, VIC TOS3 & VIC-TOS3 & 03 July - 01 November 2018 & 11.5 \\
Narrabri, NSW TOS1 & NSW-TOS1 & 17 May - 14 September 2019 & 13.1 \\
Narrabri, NSW TOS2 & NSW-TOS1 & 15 July - 19 October 2019 & 14.3 \\
Simulated cool season 1 & SIM-C1 & 103 (77) days ${ }^{4}$ & 12.9 \\
Simulated cool season 2 & SIM-C2 & 104 (78) days & 12.0 \\
Simulated warm season 1 & SIM-W1 & 83 (57) days & 17.0
\end{tabular}




\begin{tabular}{llll}
\hline Environment $^{1}$ & Environment ID & Growing period (sowing to anthesis) & Growing period (sowing to anthes \\
\hline Simulated warm season 2 & SIM-W2 & $84(58)$ days & 17.1 \\
\hline
\end{tabular}

${ }^{1}$ TOS1, 2 and 3 indicates time of sowing 1, 2 and 3, respectively; VIC, Victoria; NSW, New South Wales. ${ }^{2}$ Anthesis refers to when about $50 \%$ of plants were between early and late flowering (Zadoks growth scale between 59 and 70; Zadoks et al., 1974). ${ }^{3}$ Mean environmental conditions for the simulated environments do not include the period prior to when plants were transferred to the growth capsules for the desired simulated growth conditions; ${ }^{4}$ Values in parenthesis indicate the actual period plants were treated to the simulated growing conditions.

Table 2. Estimates of wheat $T$ crit means for each environment and estimates of their genetic and residual variances, and broad-sense heritability from the diagonal model of the MET analysis. The diagonal genetic variance model is a baseline model that assumes independence of genetic effects between environments (analogous to analysing each environment separately).

\begin{tabular}{lllllll}
\hline Environment $^{1}$ & Environment ID & $n$ genotypes & Mean $( \pm$ SE $)$ & Range & Genetic variance $\left(\sigma_{\mathrm{g}}{ }^{2}\right)$ & Residu \\
\hline Barraport West, VIC TOS1 & VIC-TOS1 & 20 & $45.0 \pm 0.3$ & $41.8-47.4$ & 0.32 & 1.24 \\
Barraport West, VIC TOS2 & VIC-TOS2 & 20 & $46.3 \pm 0.2$ & $43.9-48.6$ & 0.22 & 0.57 \\
Barraport West VIC TOS3 & VIC-TOS3 & 20 & $46.4 \pm 0.2$ & $43.8-49.2$ & 0.54 & 1.08 \\
Narrabri, NSW TOS1 & NSW-TOS1 & 24 & $45.7 \pm 0.3$ & $41.9-48.4$ & 0.18 & 0.81 \\
Narrabri, NSW TOS2 & NSW-TOS1 & 23 & $46.2 \pm 0.3$ & $43.2-48.9$ & 0.11 & 1.36 \\
Simulated cool season 1 & SIM-C1 & 50 & $43.6 \pm 0.2$ & $42.2-45.5$ & 0.20 & 0.12 \\
Simulated cool season 2 & SIM-C2 & 50 & $43.1 \pm 0.1$ & $40.2-44.9$ & 0.19 & 0.39 \\
Simulated warm season 1 & SIM-W1 & 50 & $43.6 \pm 0.2$ & $41.2-45.5$ & 0.17 & 0.20 \\
Simulated warm season 2 & SIM-W2 & 50 & $43.3 \pm 0.1$ & $41.0-45.2$ & 0.26 & 0.15 \\
\hline
\end{tabular}

${ }^{1}$ TOS1, 2 and 3 indicates time of sowing 1, 2 and 3, respectively; VIC, Victoria; NSW, New South Wales.

Table 3. Genetic variance models, total number of parameters, Akaike information criterion (AIC), residual log-likelihood (loglik), and percentage variance accounted for (\% VAF) of the diagonal variance model and factor analytic (FA) models of increasing order fitted to the genetic effects for the wheat $T$ crit MET dataset. The FA models are denoted by $\mathrm{FA}_{\mathrm{n}}$ (a factor analytic model of order $n$ ).

\begin{tabular}{lllll}
\hline Model & $n$ parameters & AIC & loglik & $\%$ VAF \\
\hline Diagonal & 67 & 690 & -278 & \\
FA $_{1}$ & 76 & 655 & -252 & 42.2 \\
FA $_{2}$ & 81 & 656 & -247 & 55.6 \\
FA $_{3}$ & 87 & 662 & -244 & 64.8 \\
FA $_{4}$ & 90 & 665 & -243 & 95.0 \\
FA $_{5}$ & 95 & 677 & -242 & 95.3 \\
\hline
\end{tabular}

Table 4. REML estimates of rotated factor loadings (first factor, $\Lambda_{1}$; and second factor, $\Lambda_{2}$ ) and percentage variance accounted for $(\% \mathrm{VAF})$ from the $\mathrm{FA}_{2}$ model fitted to the wheat $T$ crit genetic effects.

\begin{tabular}{lllllll}
\hline Environment & Environment ID & Rotated factor loadings & Rotated factor loadings & \%VAF & \%VAF & \%VAl \\
\hline & & $\Lambda_{1}$ & $\Lambda_{2}$ & $\Lambda_{1}$ & $\Lambda_{2}$ & $\Lambda_{1}+$ \\
Barraport West TOS1 & VIC-TOS1 & 0.463 & -0.086 & 62.9 & 2.2 & 65.1
\end{tabular}




\begin{tabular}{lllllll}
\hline Environment & Environment ID & Rotated factor loadings & Rotated factor loadings & \%VAF & \%VAF & \%VAl \\
\hline Barraport West TOS2 & VIC-TOS2 & 0.367 & 0.158 & 50.9 & 9.5 & 60.3 \\
Barraport West TOS3 & VIC-TOS3 & 0.022 & 0.159 & 0.1 & 4.7 & 4.8 \\
Narrabri TOS1 & NSW-TOS1 & 0.308 & 0.034 & 52.4 & 0.6 & 53.1 \\
Narrabri TOS2 & NSW-TOS1 & 0.214 & 0.098 & 82.8 & 17.2 & 100.0 \\
Simulated cool season 1 & SIM-C1 & 0.414 & 0.164 & 86.4 & 13.6 & 100.0 \\
Simulated cool season 2 & SIM-C2 & 0.364 & -0.002 & 70.5 & 0.0 & 70.5 \\
Simulated warm season 1 & SIM-W1 & 0.276 & -0.306 & 58.9 & 55.1 & 100.0 \\
Simulated warm season 2 & SIM-W2 & 0.394 & -0.091 & & 3.1 & 61.7 \\
\hline
\end{tabular}

TOS1, 2 and 3 indicates time of sowing 1, 2 and 3, respectively; VIC, Victoria; NSW, New South Wales.

Table 5. Spearman's rank correlation coefficients $(\rho)$ for correlations between the rotated factor loadings (first factor, $\Lambda_{1}$; and second factor, $\Lambda_{2}$ ) of the $\mathrm{FA}_{2}$ model and environmental covariates for wheat $T$ crit.

\begin{tabular}{|c|c|c|c|c|c|c|}
\hline Growth period & Mean daily & Mean daily & Mean daily & Mean daily & Mean daily & Mean daily \\
\hline \multirow[t]{2}{*}{ Growth period } & Temperature & Temperature & & Relative humidity & Relative humidity & \\
\hline & $\Lambda_{1}$ & $\Lambda_{2}$ & & $\Lambda_{1}$ & $\Lambda_{2}$ & \\
\hline $1 \mathrm{DBM}^{1}$ & $-0.67^{*}$ & 0.05 & & 0.43 & -0.03 & \\
\hline $3 \mathrm{DBM}$ & -0.34 & 0.05 & & 0.37 & -0.12 & \\
\hline $7 \mathrm{DBM}$ & $-0.48^{*}$ & 0.13 & & 0.30 & $-0.50^{*}$ & \\
\hline $10 \mathrm{DBM}$ & $-0.63^{*}$ & 0.28 & & 0.30 & $-0.50^{*}$ & \\
\hline $20 \mathrm{DBM}$ & $-0.65^{*}$ & 0.38 & & $0.48^{*}$ & -0.10 & \\
\hline $30 \mathrm{DBM}$ & $-0.67^{*}$ & -0.05 & & $0.52^{*}$ & -0.09 & \\
\hline Sowing to measurement & $-0.67^{*}$ & -0.05 & & $0.77^{* *}$ & 0.13 & \\
\hline
\end{tabular}

${ }^{1}$ Day before measurement of $T$ crit. ${ }^{*}$, and $* *$ indicates significance at $P[?] 0.05$, and $P[?] 0.01$, respectively. In bold are the highest correlation of environmental variables with the first rotated factor loadings for each defined growth period.

\section{Figure Legends}

Figure 1. Genotypic correlation matrix for wheat $T$ crit for nine environments, ordered by agglomerative hierarchical clustering. A scale for the genotypic correlation is depicted by the colour scale on the right, with a positive and perfect genotypic correlation between environments indicated by 1 and a perfect and negative correlation indicated by -1 . Estimated correlation coefficients for pairs of environments are indicated within the cells. The nine environments were from field trials in Victoria (Barraport West TOS1 [VIC TOS1], Barraport West TOS2 [VIC-TOS2], and Barraport West TOS3 [VIC-TOS3]), and New South Wales (Narrabri TOS1 [NSW-TOS1] and Narrabri TOS2 [NSW TOS2]), as well as simulated wheat growing seasons in Canberra (simulated cool season 1 [SIM-C1], simulated cool season 2 [SIM-C2], simulated warm season 1 [SIM-W1] and simulated cool season 2 [SIM-W2]).

Figure 2. Best linear unbiased predictions of overall performance (OP) versus root mean square deviation (RMSD, a measure of sensitivity of OP across environments) for photosynthetic heat tolerance $(T$ crit $)$ of 54 wheat genotypes, evaluated in nine environments. Seven commercial cultivars commonly grown by farmers are labelled alongside the highest and lowest ranked four genotypes (according to OP). 


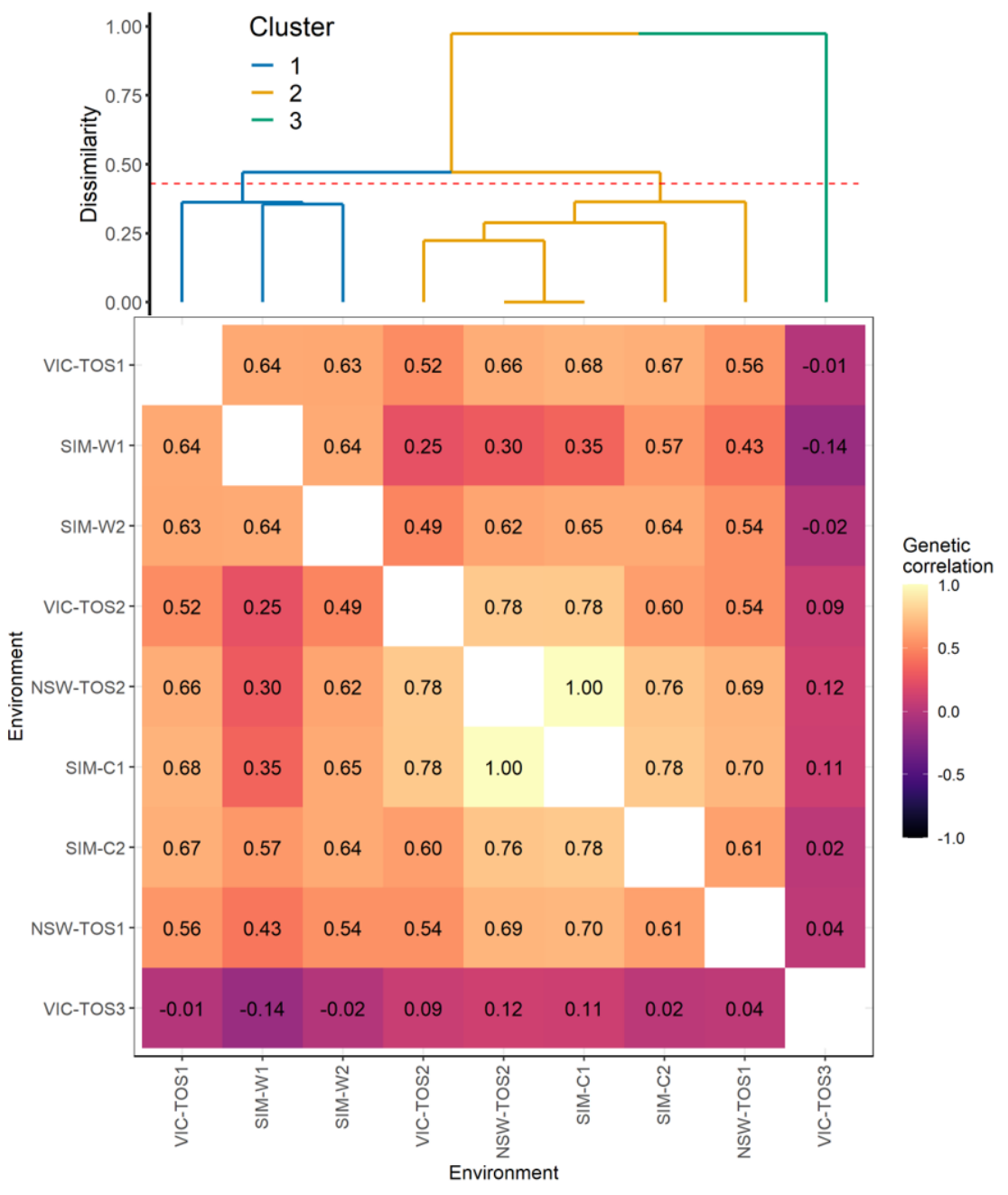




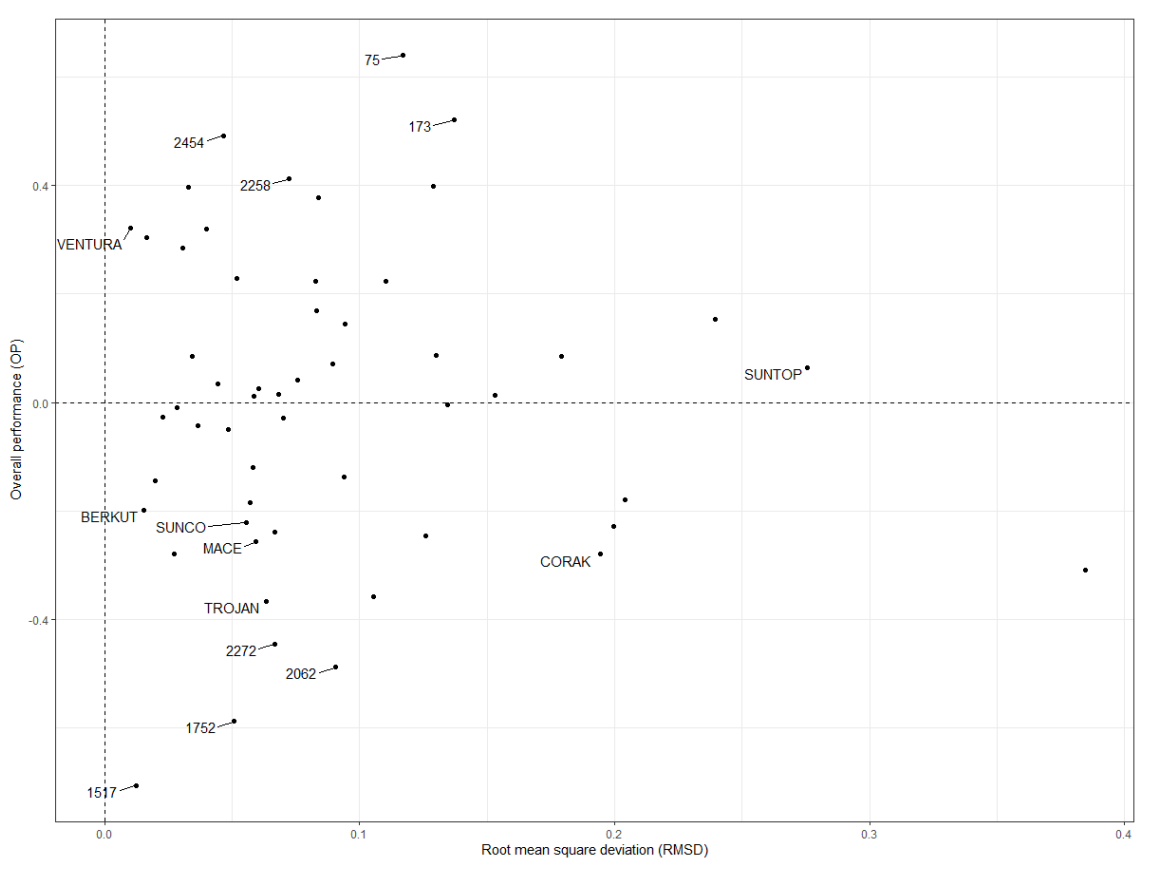

